\title{
Selection of stain fungi on rubberwood (Hevea brasiliensis) and its growth response against chitosan
}

\author{
ALI BIN ABITHALIB SALMAN ${ }^{1}$, LISDAR IDWAN SUDIRMAN ${ }^{1, \bullet}$, DODI NANDIKA ${ }^{2}$ \\ ${ }^{1}$ Department of Biology, Faculty of Mathematics and Natural Sciences, Institut Pertanian Bogor. Jl. Agatis, Kampus IPB Dramaga, Bogor 16680, West \\ Java, Indonesia. Tel./fax.: +62-251-8622833, "email: lisdar.sudirman@yahoo.co.id \\ ${ }^{2}$ Department of Forestry Products, Faculty of Forestry, Institut Pertanian Bogor. Jl. Ulin, Kampus IPB Dramaga, Bogor 16680, West Java, Indonesia
}

Manuscript received: 30 July 2020. Revision accepted: 7 September 2020.

\begin{abstract}
Salman ABA, Sudirman LI, Nandika D. 2020. Selection of stain fungi on rubberwood (Hevea brasiliensis) and its growth response against chitosan. Biodiversitas 21: 4501-4508. Rubberwood (Hevea brasiliensis Muell.Arg.) is one of the most important raw materials in furniture industry in South East Asian countries, particularly in Indonesia, Thailand and Malaysia. However, due to its susceptibility to stain fungi attack, wood preservative is needed to processing this material, which has both significant cost and environmental implications. A laboratory study was conducted to identify the seasoned rubberwood attacking stain fungi and to evaluate the bioactivity of chitosan in inhibiting the stain fungi's growth. Isolation fungi from seasoned rubberwood were obtained firstly then selection isolates were conducted in the rubberwood test samples. Isolates with the highest percentage growth on wood test samples would identify based on internal transcribed spacer (ITS) region. Chitosan were prepared in four concentration $0,0.5,1$ and $2 \%$ (w/v). Two isolates were showed the highest percentage growth on wood test samples after six weeks, which were $90.6 \%$ for isolate I4 and 96.2\% for II4 and both isolates gained scores 5. The two isolates were identified as Aspergillus foetidus for I4 and Aspergillus aflatoxiformans for II4. Aspergillus foetidus and A. aflatoxiformans would be the newly recorded species and these are the first report about species description from rubberwood in Indonesia. The inhibition rate was increased when chitosan concentration was increased from 0 to $2 \%$. Chitosan concentration $2 \%$ inhibited the growth of A. foetidus in $20.28 \%$, but there is no inhibition showed on A. aflatoxiformans. The addition of chitosan in medium can increase the growth of A. aflatoxiformans and forming clear zone around the colony.
\end{abstract}

Keywords: Aspergillus aflatoxiformans, Aspergillus foetidus, chitosan, ITS region, rubberwood

\section{INTRODUCTION}

Rubberwood (Hevea brasiliensis Muell.Arg) is one of the hardwood species that is native from tropical rain forest, Brazil. Rubberwood firstly planted in Indonesia and Malaysia for rubber sap production. The wood has bright color, medium brown streak, the average of density in 0.6 $\mathrm{g} / \mathrm{cm}^{3}$, modulus of rupture (MOR) in $103 \mathrm{MPa}$, modulus of elasticity (MOE) in $9900 \mathrm{MPa}$, tensile strength in 1.4-1.9 $\mathrm{MPa}$, and hardness in $6000 \mathrm{~N}$. Therefore, rubberwood widely used as furniture, particle wood, wood floors, plywood and sawn timber (Riyaphan et al. 2015). On the other hand, rubberwood has low natural durability that makes it susceptible to attack by stain fungi as mold or blue stain fungi. Stain fungi is filamentous fungi that cause discolorization on wood surface like blue, greyish, green and black. The colorization influenced by melanin crystallization around hyphae or from secretion of extracellular material. Stain fungi do not affect of strength loss, but decrease the aesthetic and cost of wood. Previous studies reported that three stain fungi were identified from rubberwood, which were Aspergillus niger, Aspergillus flavus, and Penicillium citrinum (Oldertrøen et al. 2016). In fact, stain fungi were found to attack the part of piano produced by one company in Indonesia.

Many case wood that attacked by stain fungi became the main reason of some industry to preserving wood with chemicals compound. However, most of chemicals are harmful to humans and environment. Wilson et al. (2014) reported that $80 \%$ residue of fungicide azoxystrobin and $71 \%$ boscalid found in fly larva which is not as main target. Furthermore, other results report that methylene dithiocyanate as an active compound of fungicide can also cause respiratory disorder and death. Based on these negative impacts, many studies conducted to find preservatives that are safe for humans and environment. One of the natural materials that can be used as wood preservatives is chitosan.

Chitosan is unbranched polymer that consists of glucosamine $(\mathrm{GlcN})$ and $\mathrm{N}$-acetyl glucosamine (GlcNAc). The polymer has the potency to be used as wood preservative considering its properties, such as biodegradable, non-toxic, abundant, antimicrobial, and antifungal activity (Zivanovic et al. 2015). Some studies are reporting the activity of chitosan inhibited stain fungi. Waewthongrak et al. (2015) confirmed that chitosan can inhibit the growth of Penicillium digitatum. The addition of chitosan concentration 1 and $5 \mathrm{mg} \mathrm{mL}^{-1}$ in potato dextrose agar (PDA) medium showed $100 \%$ inhibition rate, while the diameter colony of control was $20.5 \mathrm{~mm}$ after five days incubation. On the other hand, chitosan only gives $40 \%$ spore viability of Aspergillus parasiticus, whereas control with $100 \%$ spore viability (Hernández-téllez et al. 2017). 
More recently, Da Silva et al. (2018) reported that chitosan inhibited the growth of Aspergillus flavus. The sample showed only $35.34 \pm 4.04 \%$ infection at chitosan concentration $2 \mathrm{gL}^{-1}$, while control has the highest infection $100 \%$ after seven days incubation. Several studies reported that chitosan concentration $0.01 \%$ caused damage in plasma membrane and cytoplasm material, whereas the higher concentration of chitosan $(0.15 \%)$ caused higher destruction of membrane structure and complete loss of cytoplasm integrity of Sphaeropsis sapinea (Singh et al. 2008). This was also reported by Divya et al. (2018) that chitosan showed damage to membrane permeability and abnormality of cell Rhizoctonia solani, Fusarium oxysporum, Colletotrichum acutatum, and Phytophthora infestans. Since there is no research about isolate and identify stain fungi from rubberwood and in vitro assay of chitosan against stain fungi in Indonesia, the aim of present study was to identify stain fungi on seasoned rubberwood and determine the antifungal activity of chitosan.

\section{MATERIALS AND METHODS}

\section{Isolation and selection of fungi}

Rubberwood sample that infected by stain fungi were obtained from the one company in Indonesia. Wood samples were cut in $2 \times 2 \times 1 \mathrm{~cm}$ and soaked in aquadest for 24 hours and then treated with surface sterilization based on Hughes et al. (2018) with modification. The wood samples were soaked in sterile aquadest for two minutes and shaken occasionally. This process was carried out in five times and then passed on fire slightly (Sudirman 2018, pers. com). The woods were incubated in PDA medium for seven days at room temperature $\left(28 \pm 2^{\circ} \mathrm{C}\right)$. The tip of hyphae was taken and cultivated in PDA for purification.

The purified isolates were then selected to observe percentage growth of wood test samples. Wood test samples were prepared with size $5 \times 1 \times 0.5 \mathrm{~cm}$ and sterilized in autoclave for $121^{\circ} \mathrm{C}$ for 15 minutes. Sterile wood test samples and each isolate stain fungus were put in Petri dish $(\varnothing=9 \mathrm{~cm})$ and incubated for six weeks incubation at room temperature $\left(28 \pm 2^{\circ} \mathrm{C}\right)$ based on European Standard 152 (1984) with modification. The wood test samples were removed after six weeks and dried up at $60^{\circ} \mathrm{C}$ for three days. The percentage growth of isolate to the surface area of the wood test samples was represented by score. Score 0 indicated that there is no growth of isolate on wood test samples and scores 5 indicated the heavy stain fungi growth, which was 0: no growth, 1: $20 \%$ growth of stain fungi on wood test samples, 2: 40\%, 3: 60\%, 4: 80\% and 5: $100 \%$ (Jantamas et al. 2013).

\section{Morphological identification of stain fungi}

Morphological identification was carried out on isolates that had the highest score on wood test samples. The isolates were cultivated in the center of malt extract agar (MEA) medium at room temperature $\left(28 \pm 2^{\circ} \mathrm{C}\right)$ for macroscopic analysis based on Silva et al. (2011). Microscopic analysis was conducted by cultivated the isolates in three points on MEA for seven days at room temperature $\left(28 \pm 2^{\circ} \mathrm{C}\right)$. Macroscopic analysis includes colony diameter, colony color of the top, and bottom, while microscopic analysis includes conidia diameter, conidia shape, hyphae, present of metulae, and size of vesicle (Samson et al. 2014).

\section{Molecular identification of stain fungi}

Molecular identification was carried out using services from IPB Culture Collection (IPBCC), Department of Biology, Faculty of Mathematics and Natural Sciences, Bogor Agricultural University. Identification was conducted based on selected isolate from stain fungi selection. DNA extraction was conducted by using Sodium Dodecyl Sulfate (SDS) for lysis cells. PCR composition was prepared with a total composition of $10 \mu \mathrm{L}$ that consisting of $2 \mu \mathrm{L}$ of My Taq mastermix, $6.5 \mu \mathrm{L}$ of nuclease-free water, $1 \mu \mathrm{L}$ of DNA template, and $0.25 \mu \mathrm{L}$ of each primer. Two primer used for amplifying rDNA ITS region were ITS4 (TCCTCCGCTTATTGATATGC) and ITS5 (GGAAGTAAAAGTCGTAACAAGG). The PCR condition was as follows: predenaturation in 5 minutes at $95^{\circ} \mathrm{C}$, denaturation at $95^{\circ} \mathrm{C}$ for $30 \mathrm{~s}$, annealing at $54^{\circ} \mathrm{C}$ for 1 minute, elongation at $72^{\circ} \mathrm{C}$ for 2 minutes, post elongation at $72^{\circ} \mathrm{C}$ for 5 minutes, and cooling for $4^{\circ} \mathrm{C}$ for 5 minutes. The stages of denaturation, annealing, and elongation were carried out as many as 35 cycles (White et al. 1990).

Amplification results were delivered to 1 st Base DNA sequencing service, Malaysia to identify gene sequence. The sequences received were then analyzed using the ChromasPro software version 1.7.7 to make consensus sequences. Consensus sequences were then compared using BLAST through NCBI (http://www.ncbi.nlm.nih.gov/) to see similarities with sequences found in GenBank using MEGA 5 software. Phylogenetic tree was constructed based on Kimura 2-parameter and Neighbour-joining (NJ) with bootstrap 1000 replicates.

\section{Bioactivity test of chitosan against stain fungi}

Chitosan was obtained from Aquatic Product Technology Laboratory, Faculty of Fisheries and Marine Sciences, Bogor Agricultural University, Bogor, Indonesia. Chitosan powder from shrimp shells was dissolved in acetic acid $2 \%(\mathrm{w} / \mathrm{v})$ to make concentration $0,0.5,1$, and $2 \%$. The solution was then blended to get a good mixture.

The effect of chitosan on mycelial growth was evaluated in solid medium. PDA medium and chitosan solution were sterilized for 15 minutes at $121^{\circ} \mathrm{C}$, separately. Sterile PDA medium $(15 \mathrm{~mL})$ was poured into Petri dish and mixed with $1 \mathrm{~mL}$ chitosan solution with each concentration. PDA medium mixed with acetic acid $2 \%$ was prepared as a control (Dewi and Nur 2017). Inhibitory effect was conducted by inoculating a $0.5 \mathrm{~cm}$ diameter isolate in PDA and incubated for seven days at room temperature $\left(28 \pm 2^{\circ} \mathrm{C}\right)$. The experiments were repeated in three replicates. Determination of the percentage of growth inhibition is based on previous research with formulations (Pratheesh et al. 2017): 


$$
\mathrm{PIDG}=\frac{\mathrm{D} 1-\mathrm{D} 2}{\mathrm{D} 1} \times 100
$$

Where:

PIDG: Percentage of Inhibition of Diameter Growth (\%)

D1 : Colony diameter in control plates $(\mathrm{cm})$

D2 : Colony diameter in test plates $(\mathrm{cm})$

The experiments were analyzed by one-way analysis of variance (ANOVA) with four chitosan treatments, which were: [P1]: $2 \%,[\mathrm{P} 2]$ : $1 \%,[\mathrm{P} 3]$ : $0.5 \%$ and [P4]: control with acetic acid $2 \%$. The difference of mean was determined by Duncan based on $95 \%$ confidence interval using SPSS software version 22.

\section{RESULTS AND DISCUSSION}

\section{Stain fungi isolates and its discolorization effects}

There were eight isolates obtained from seasoned rubberwood after seven days incubation and two isolates showed the highest percentage growth on the surface area of the wood test samples for six weeks, which were $90.6 \%$ for isolate I4 and $96.2 \%$ for isolate II4. Based on the percentage of growth, both isolates were given scores 5 (Figure 1).

The stain fungi that have been obtained probably belong to the blue stain or sap stain fungi group and not to the mold group. The discoloration of wood caused by the melanin of fungi that persist in wood even after the fungus death. The blue stain fungi have the ability to penetrate deeper into wood compared to mold that only grows on the wood surface. It is caused by the hyphae that penetrate from the pits in wood or directly through the cells by forming boreholes (Daniel 2016). Therefore, the blue stain fungi can not be removed by brushing treatment, in contrast to mold fungi. Based on this condition, many parts of wood will be wasted to remove blue stain and caused dimensional changes on wood.

The ability of stain fungi to grow on wood was caused by the presence of simple sugars and starches as a source of nutrition. Schmidt et al. (2016) in his research informed that $A$. niger was able to colonize wood samples in firstweek incubation depends on the condition of substrates rich in glucose and starch of 162.3 and $33.5 \mathrm{nmol} \mathrm{mg-1}$ respectively. Another study also reported that the carbohydrate content most commonly found in rubberwood is starch (Ketkakomol et al. 2014). Stain fungi do not attack cellulose, hemicellulose, and lignin so that high weight loss does not occur in wood. Stain fungi will reduce the economic value due to decrease in the aesthetic of wood. Another research had stated that the presence of stain fungi on wood was increased the water absorption. The higher water sorption, the higher moisture content. Based on this condition, the higher moisture content will increase the possibility of the growth of decay fungi (Feng et al. 2014).
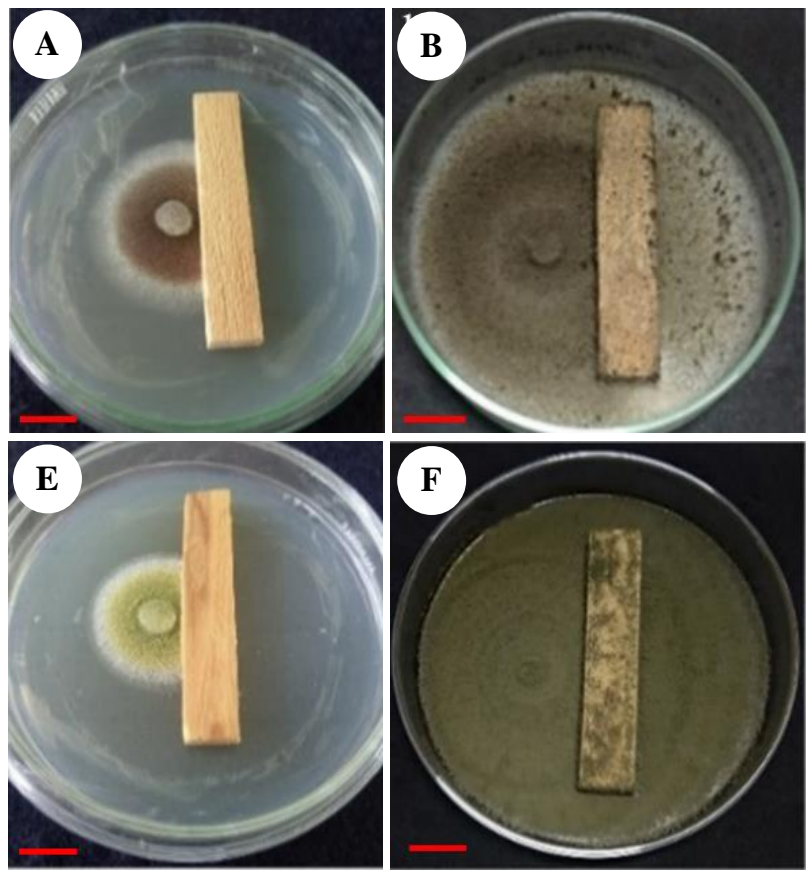

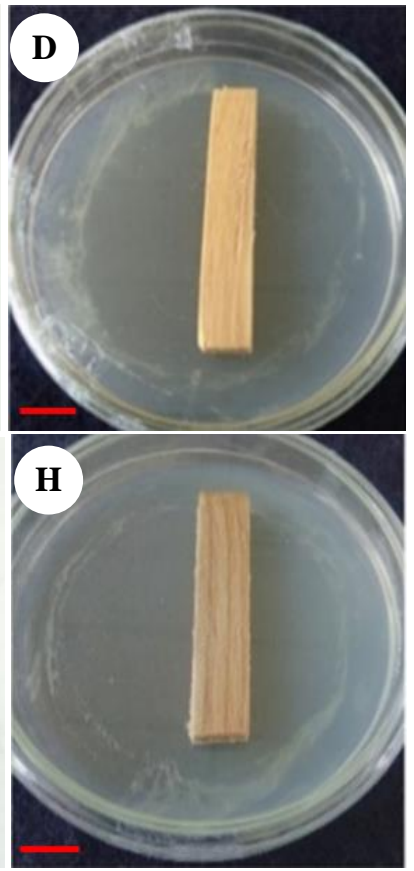

Figure 1. Selected isolates were I4 (top) and II4 (bottom) on the rubberwood test samples. A and E. Wood before being attacked by stain fungi, B and F. Wood when attacked by stain fungi, C and G. Wood after being attacked by stain fungi, D and H. Controls. Scale bar $=1 \mathrm{~cm}$ 

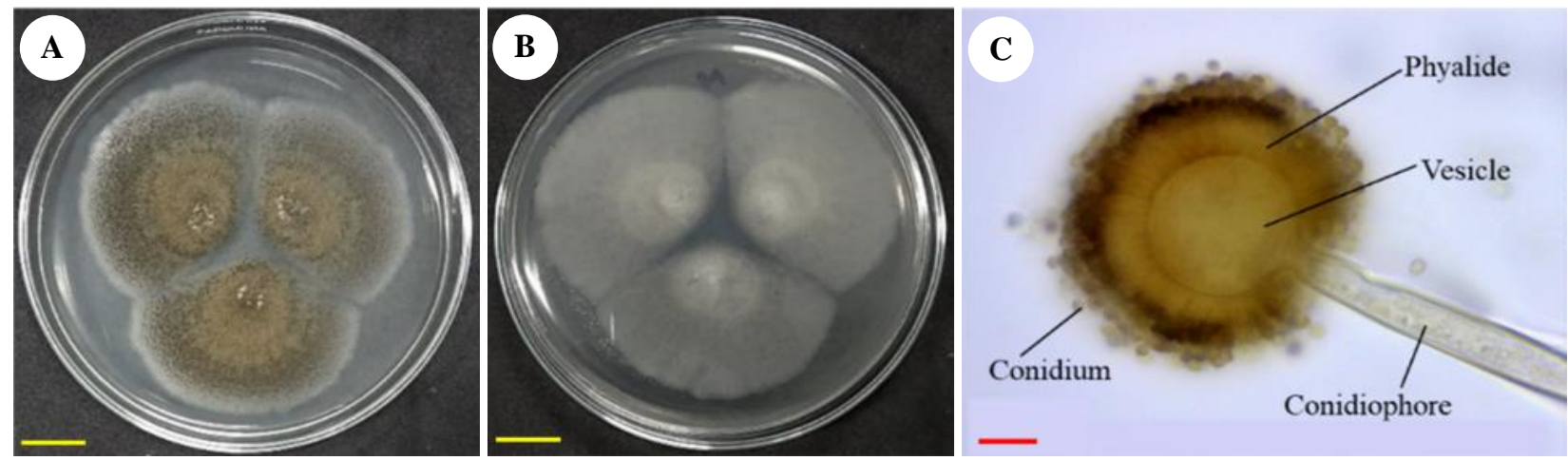

Figure 2. Characteristics of Isolate I4. A. Colony at above view, B. Colony at reverse view, C. Microscopic structure. Scale bar: A and $\mathrm{B}=1 \mathrm{~cm}, \mathrm{C}=10 \mu \mathrm{m}$
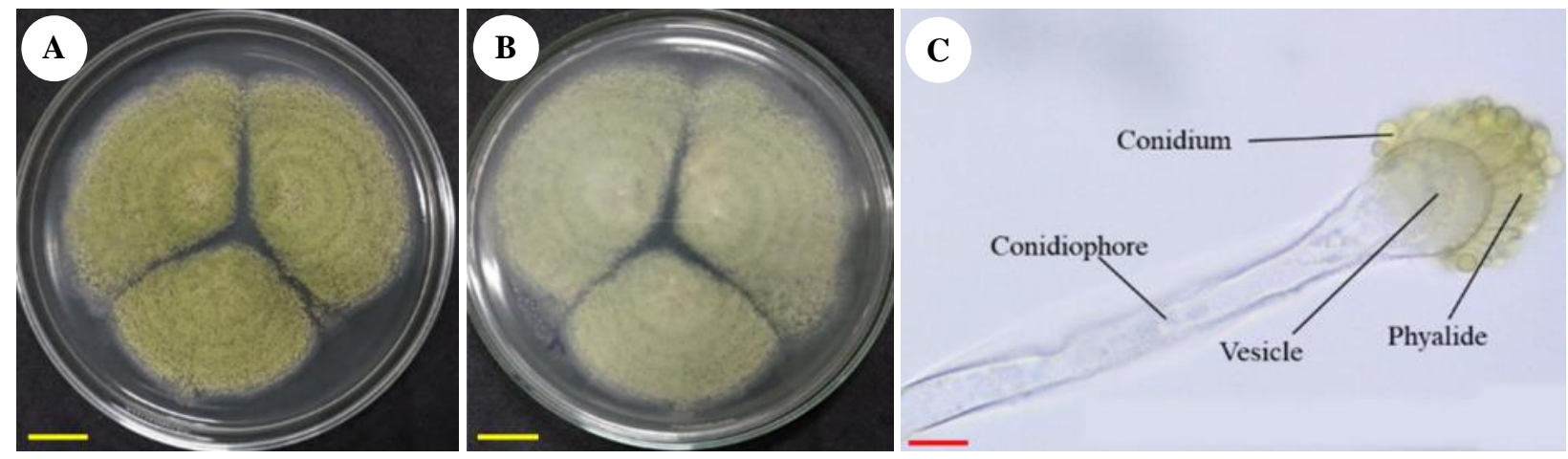

Figure 3. Characteristics of Isolate II4. A. Colony at above view, B. Colony at reverse view, C. Microscopic structure. Scale bar: A and $\mathrm{B}=1 \mathrm{~cm}, \mathrm{C}=10 \mu \mathrm{m}$

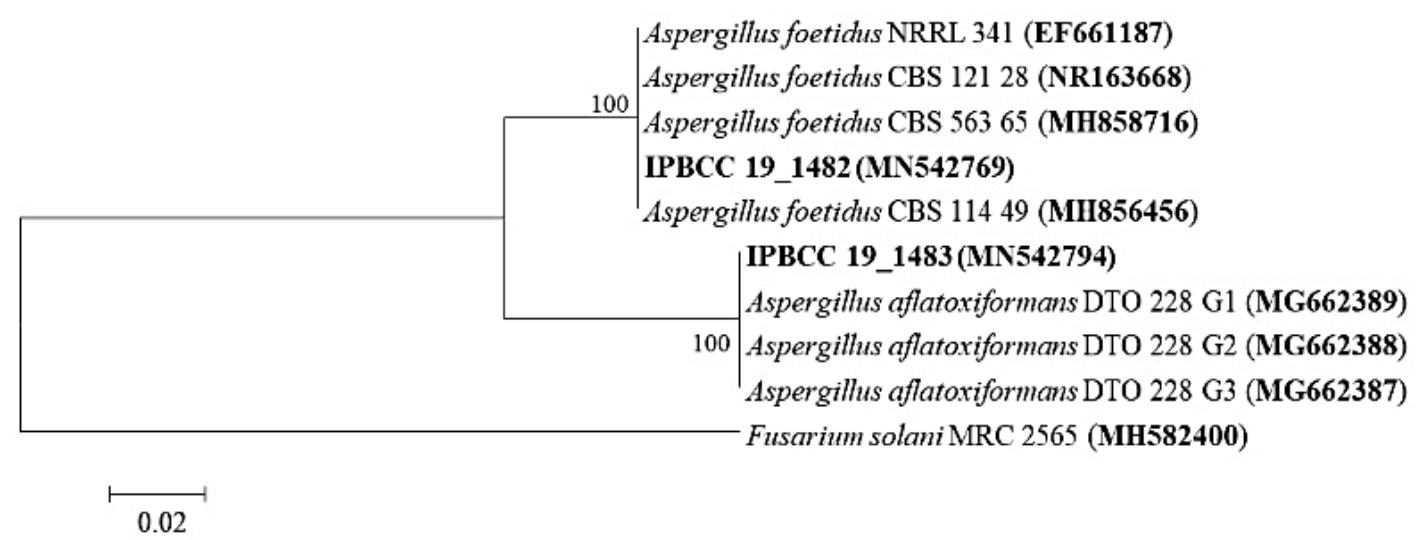

Figure 4. Neighbor-joining of isolates IPBCC 19.1482 (I4) and IPBCC 19.1483 (II4) with Fusarium solani as outgroup

\section{Morphology of stain fungi}

Isolate I4 has macroscopic character consisting of a colony that was black at the top and pale white at reverse color, and the colony diameter in $7.35 \mathrm{~cm}$ after seven days incubation in MEA at room temperature $\left(28 \pm 2^{\circ} \mathrm{C}\right)$. In microscopic structures, isolate I4 showed the hyaline of vegetative hyphae and conidiophore, uniseriate (absence of metulae), septate hyphae, vesicle size 28.82 (28.15-29.20) $\mu \mathrm{m}$ with globose shape, conidia size 2.85 (2.09-3.09) $\mu \mathrm{m}$ with globose shape and brownish color (Figure 2).

The observation values obtained are different from Silva et al. (2011) that observed Aspergillus foetidus. Previous study reported that size of colony diameter and conidia were $6.2-6.6 \mathrm{~cm}$ and $4-5 \mu \mathrm{m}$ respectively after 
seven days incubation in MEA medium at $25^{\circ} \mathrm{C}$. The differences were thought to be due to the influence of temperature, giving a physiological effect on the species of fungi. Another reference informed that there is a different growth among black Aspergillus when cultivated in different temperatures during ten days. The optimal growth was showed at temperature $33-36^{\circ} \mathrm{C}$, while in lower temperature $\left(15^{\circ} \mathrm{C}\right)$ the growth was still found with smaller colony diameters (Meijer et al. 2011).

Isolate II4 has the macroscopic characters consisting of a colony that was yellow green at the top and pale green at reverse color, and the colony diameter in $8.30 \mathrm{~cm}$ after seven days incubation in MEA at room temperature $\left(28 \pm 2^{\circ} \mathrm{C}\right)$. In microscopic structures, isolate II 4 showed the hyaline of vegetative hyphae and conidiophore, uniseriate (absence of metulae), septate hyphae, vesicle size in 19.96 (16.67-22.19) $\mu \mathrm{m}$ with subclavate shape, conidia size in $2.85(2.18-3.84) \mu \mathrm{m}$ with globose shape and yellowishgreen color (Figure 3).

These observations have similarities with the results from Frisvad et al. (2019) that observed Aspergillus aflatoxiformans with macroscopic characters were white mycelium and yellow-green color of conidia. Based on microscopic analysis, A. aflatoxiformans showed yellowgreen conidia, uniseriate, hyaline conidiophore, vesicle size 23-38 $\mu \mathrm{m}$, and conidia size of 3.5-5 and 3-4.5 $\mu \mathrm{m}$ in MEA medium at $25^{\circ} \mathrm{C}$ during seven days incubation.

\section{Phylogenetic of stain fungi}

The results of molecular identification are presented on phylogenetic tree (Figure 4). Isolate I4 has $100 \%$ similarities with Aspergillus foetidus with accession number of MN542769, whereas isolate II4 is $100 \%$ closer to Aspergillus aflatoxiformans with accession number of MN542794. The isolates were then stored in IPB Culture Collection (IPBCC) with the code IPBCC 19.1482 for isolate I4 and IPBCC 19.1483 for II4.

Based on these results, the stain fungi isolates obtained from rubberwood are different results with Oldertrøen et al. (2016) who obtained Aspergillus niger, Aspergillus flavus, and Penicillium citrinum. However, these results still showed the similarities in genus level. Some studies reported that Aspergillus can also be found in spruce wood (Picea canadensis), other products that are made from wood, and decayed wood (Emoghene et al. 2014; AbdelAzeem et al. 2019; Al-tememe et al. 2019). This suggests that Aspergillus spp. has the ability to grow on a variety of substrates.

Aspergillus foetidus is a fungus that is included in the Aspergillus section Nigri and can be found on various substrates apart from rubberwood. Another study reported that $A$. foetidus had been isolated and identified from raisins, beans, coffee, and chocolate (Silva et al. 2011). Based on the references, it was found that A. foetidus had been isolated and stored in one of the culture collections in Indonesia, but the isolates obtained were not from rubberwood. Hence, A. foetidus would be a new record in Indonesia regarding the distribution and description of its colony. Aspergillus aflatoxiformans that was obtained relatively new and has not been recorded at several culture collections in Indonesia. The isolate was grouped in Aspergillus section Flavi that first discovered by Frisvad et al. in its publication in 2019. Aspergillus aflatoxiformans were first identified from agricultural soil, stored rice grains, and sesame kernels from market in Nigeria, while our result this species was obtained from rubberwood. According to this consideration, A. aflatoxiformans would be a new record for Indonesia.

\section{Bioactivity of chitosan on stain fungi}

The increase of chitosan concentration was showed negative response to the growth of A. foetidus. In all experiments, addition of chitosan in PDA medium showed the inhibition in each concentration after seven days incubation. This research had shown that the largest growth diameter was in the control of $9 \mathrm{~cm}$, while the smallest diameter was found in chitosan $2 \%$ of $7.18 \mathrm{~cm}$ (Figure 5).

The highest growth inhibition of $2 \%$ chitosan concentration was $20.28 \%$. Analysis of variance showed that addition of chitosan significantly affected the growth of A. foetidus. Based on the differences among mean, concentration $2 \%$ distinctly different among other treatments (Figure 6).
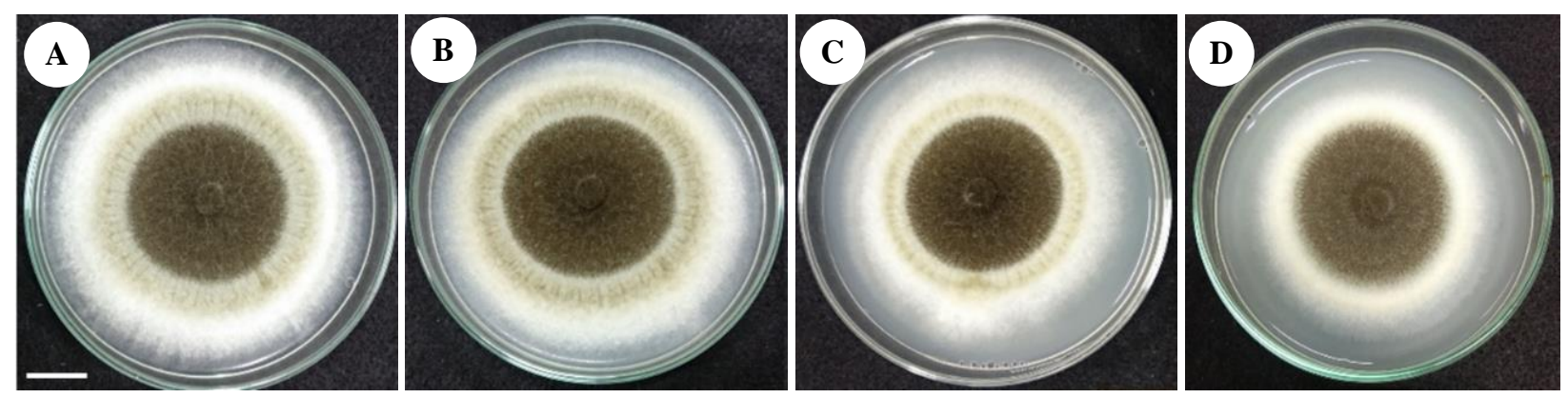

Figure 5. Growth of Aspergillus foetidus on PDA medium with various chitosan concentration. A. Control acetic acid $2 \%$, B. Chitosan $0.5 \%$, C. Chitosan $1 \%$, D. Chitosan $2 \%$. Scale bar $=1 \mathrm{~cm}$ 


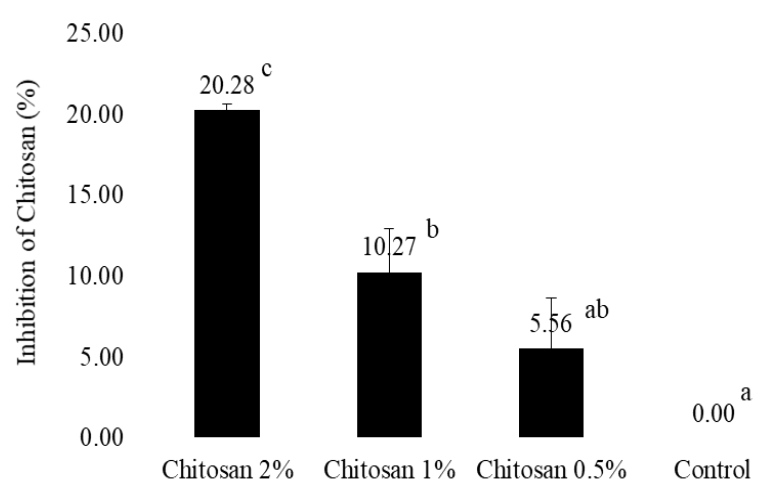

Figure 6. Percentage of growth inhibition of Aspergillus foetidus. The same letters indicated not significantly different of mean according to Duncan's test $(p<0.05)$

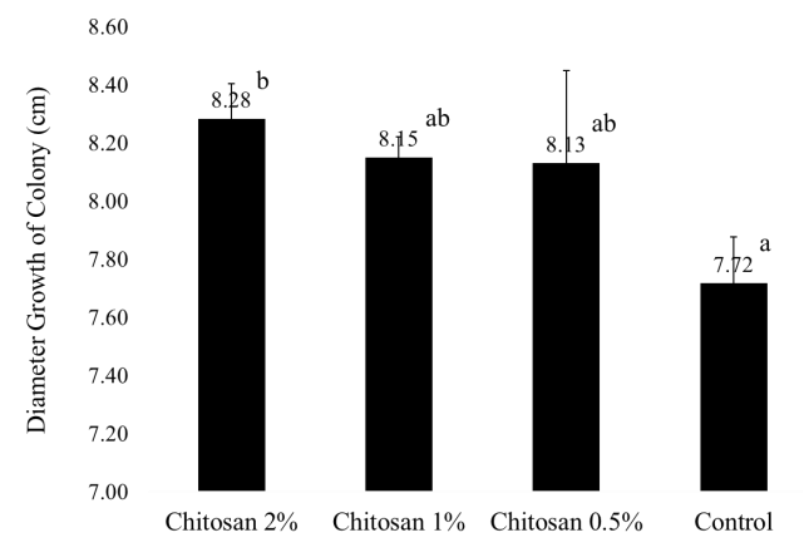

Figure 7. Diameter growth of Aspergillus aflatoxiformans. The same letters indicated not significantly different of mean according to Duncan's test $(p<0.05)$
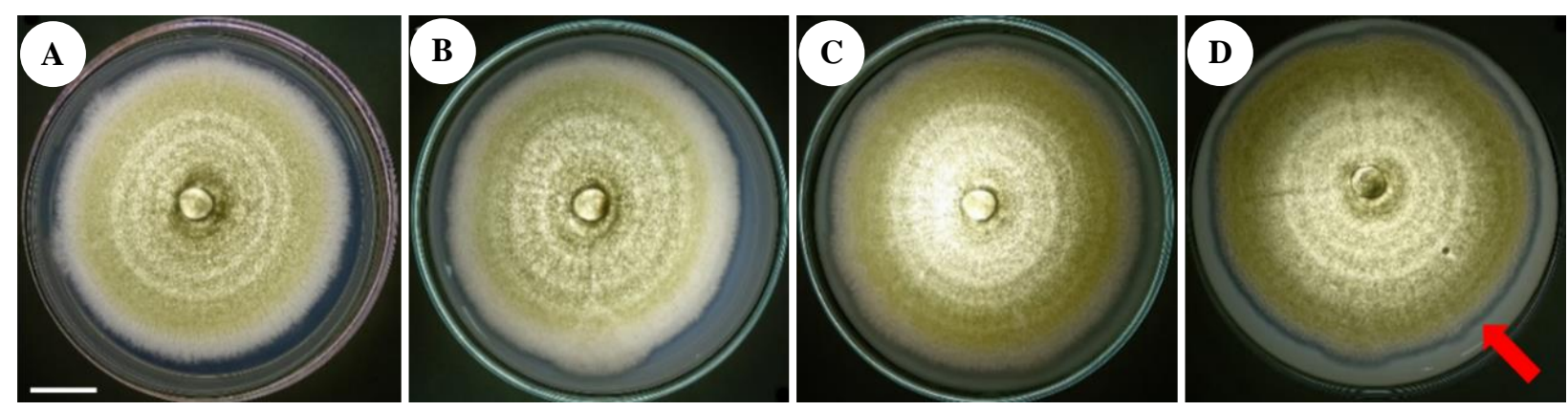

Figure 8. Clear zone of Aspergillus aflatoxiformans. A. Control acetic acid 2\%, B. Chitosan 0.5\%, C. Chitosan 1\%, D. Chitosan $2 \%$. Arrow $=$ Clear zone; Scale bar $=1 \mathrm{~cm}$

The growth of inhibition obtained was still lower than other previous study. The lower inhibition was suspected that A. foetidus resistance to chitosan. Ing et al. (2012) informed the resistance of $A$. niger to chitosan caused by high chitin content in the cell wall. The content of chitin and $\beta$-1,3-glucans in cell walls influences the tolerance of fungi to chitosan. The presence of chitin plays a role in helping maintain cell walls, whereas glucans regulate the flexibility and consistency of cell walls (Aranda-Martinez et al. 2016). The inhibition growth was suspected by the interaction between chitosan and the plasma membrane which increased the oxidative stress (Fawzya et al. 2019). Another research informed that chitosan damage membranes and penetrates into fungal cells, thereby damaging intracellular composition, for instance, inhibit the absorption of nutrients, interfere with mRNA and protein synthesis (El-Guilli et al. 2015).

On the other hand, A. aflatoxiformans showed a different response to chitosan. The addition of chitosan on PDA media showed a positive response to growth of $A$. aflatoxiformans. The higher of chitosan concentration, the higher growth of $A$. aflatoxiformans. The addition of chitosan concentration $2 \%$ showed $8.28 \mathrm{~cm}$ of colony diameter, while control only $7.72 \mathrm{~cm}$. Analysis of variance confirmed that there is no inhibition effect of chitosan to $A$. aflatoxiformans. Based on the differences among mean, concentration $2 \%$ distinctly different from control (Figure 7).

Another response was showed of A. aflatoxiformans when chitosan added to medium. There was a clear zone in medium around the colony. The clear zone was only showed by A. aflatoxiformans in the media treated with chitosan, while there was no clear zone in control medium (Figure 8).

The positive response on the growth of this isolate is suspected that A. aflatoxiformans is able to degrade chitosan in the medium by chitosanase enzyme. Nampally et al. (2015) reported that a similar response was showed by Aspergillus niger when cultivated in Luria-Bertani (LB) agar medium with addition chitosan $0.9 \%$. Another research confirmed that clear zone was also reported by $A$. flavus in chitosanase detection agar (CDA) medium after five days incubation ( $\mathrm{Zu}$ et al. 2012). The degradation of chitosan was suspected by the activity of chitosanase enzymes. Chitosanase of Aspergillus fumigatus hydrolyzed $100 \%$ chitosan with deacetylated degree of $70 \%$. This enzyme showed the ability to split $\beta-1,4$ glycosidic bonds between glucosamine (GlcN-GlcN) and $\mathrm{N}$-acetyl 
glucosamine (GlcNAc-GlcN) (Hirano et al. 2012). In addition, Zhang et al. (2015) confirmed that chitosanase subclass II was produced by A. clavatus. Chitosanase was classified into three subclasses based on the specificity of cleavage, which was subclass I that split both GlcN-GlcN and GlcNAc-GlcN linkages, subclass II can split only GlcN-GlcN linkages and subclass III can cleave both GlcN-GlcN and GlcN-GlcNAc linkages. According to this result, chitosan showed the low inhibition effect on the $A$. foetidus growth and there is no inhibition against $A$. aflatoxiformans. Therefore, in order to inhibit growth of $A$. foetidus and A. aflatoxiformans could be tested using plant or microbial extraction and other microbial secondary metabolites that have been published in several references.

In summary, A total of eight isolates of fungi were isolated from seasoned rubberwood and two of them showed the highest score of growth on wood test samples. Both isolates were identified as Aspergillus foetidus and A. aflatoxiformans and belong to the group of blue stain fungi. According to publication and distribution in culture collections, A. foetidus was not isolated and identified yet from rubberwood, therefore this isolate can also be said to be a new record in Indonesia. Based on morphological, molecular characteristics, and the search of publications and culture collections of $A$. aflatoxiformans, this isolate would be a new record in Indonesia, thereby this information was increasing the references about the habitat and distribution of A. aflatoxiformans species. The chitosan showed the various response to inhibit the growth of stain fungi. Chitosan concentration $2 \%$ was showed $20.28 \%$ growth inhibition of $A$. foetidus, while there was no growth inhibition showed of A. aflatoxiformans. The addition of chitosan concentration $2 \%$ in medium increased the growth of $A$. aflatoxiformans up to $8.28 \mathrm{~cm}$, while control only $7.72 \mathrm{~cm}$. Another response was shown by $A$. aflatoxiformans in chitosan treatment by forming a clear zone around the colony and It still unknown that the clear zone was formed by degradation of chitosan as a nutrition source or response to unfavorable environmental conditions.

\section{ACKNOWLEDGEMENTS}

We would like to thank the Hadji Kalla Foundation for financial assistance provided, Dr. Pipih Suptijah from Laboratory of Aquatic Product Technology, Faculty of Fisheries and Marine Sciences, Bogor Agricultural University, Indonesia for the knowledge and supply of chitosan, and to the IPB Culture Collection (IPBCC) for molecular services.

\section{REFERENCES}

Abdel-Azeem AM, Held BW, Richards JE, Davis SL, Blanchette RA 2019. Assessment of biodegradation in ancient archaeological wood from the middle cemetery at Abydos, Egypt. PLoS One 14 (3): 1-17. DOI: 10.1371/journal.pone.0213753.

Al-tememe Z, Lahuf AA, Kareem AA, Kadhim AA, Al-mosawy M. 2019. A survey and molecular identification of Aspergillus versicolor causing brown rot on imported spruce (Picea canadensis) wood in
Karbala province, Iraq and control it using copper boron chromate. IOP Conf Ser Earth Environ Sci 388: 012010. DOI: 10.1088/17551315/388/1/012010.

Aranda-Martinez A, Lopez-Moya F, Lopez-Liorca. 2016. Cell wall composition plays a key role on sensitivity of filamentous fungi to chitosan. J Basic Microbiol 56: 1-12.

Daniel G. 2016. Fungal degradation of wood cell walls. In: Kim YS, Funada R, Singh AP (eds) Secondary Xylem Biology: Origins, Functions, and Applications. Academic Press, London.

Da Silva LP, Bitencourt TA, Saltoratto ALF, Seleghim MHR, Assis OBG. 2018. Antifungal activity of chitosan and its quaternized derivative in gel form and as an edible coating on cut cherry tomatoes. J Agr Sci 63 (3): 271-285.

Dewi R, Nur RM. 2017. Antifungal activity of chitosan on Aspergillus spp. Int J Bioengineer Biotechnol 2 (4): 24-30.

Divya K, Vijayan S, Jisha MS. 2018. Antifungal, antioxidant and cytotoxic activities of chitosan nanoparticles and its use as an edible coating on vegetables. Int J Biol Macromol 114: 572-577.

El-Guilli M, Hamza A, Clement C, Ibriz M, Barka EA. 2015. Effectiveness of postharvest treatment with chitosan to control citrus green mold. Agriculture 6 (12): 1-15.

Emoghene AO, Okungbowa OC, Obayagbona ON, Jaboro AG. 2014. Cellulolytic activities of wild type fungi isolated from decayed wood cuttings. Nig J Biotech 27: 41-48.

European Standard 152. 1984. Test methods for wood preservativesLaboratory method for determining the protective effectiveness of a preservative treatment against blue stain in service. Part 1: Brushing procedure, Part 2: Application by methods other than brushing.

Fawzya YN, Trisdayanti, Wibowo S, Noriko N. 2019. Antifungal activity of chitosan oligomer prepared using chitosanase of Aeromonas media KLU 11.16. IOP Conf Ser: Earth Environ Sci 278: 1-10. DOI: 10.1088/1755-1315/278/1/012026.

Feng J, Shi Q, Chen Y, Huang X. 2014. Bluestain resistance and water absorption of wood/HDPE and bamboo/HDPE. J Appl Sci 14 (8): 776-783.

Frisvad JC, Hubka V, Ezekiel CN, Hong SB, Nováková A, Chen AJ, Arzanlou M, Larsen TO, Sklenar F, Mahakarnchanakul W, Samson RA, Houbraken J. 2019. Taxonomy of Aspergillus section flavi and their production of aflatoxins, ochratoxins and other mycotoxins. Stud Mycol 93: 1-63.

Hernández-téllez CN, Rodríguez-córdova FJ, Rosas-burgos EC, Cortezrocha MO, Burgos-hernández, Lizardi-mendoza, Torres-arreola W, Martínez-higuera A, Plascencia-jatomea M. 2017. Activity of chitosan-lysozyme nanoparticles on the growth, membrane integrity, and $\beta$-1,3-glucanase production by Aspergillus parasiticus. Biotech 7 (279): 1-13.

Hirano K, Arayaveersid A, Seki K. 2012. Characterization of a chitosanase from Aspergillus fumigatus ATCC13073. Biosci Biotechnol Biochem 76 (8): 1523-1528.

Hughes KA, Misiak M, Ulaganathan Y, Newsham KK. 2018. Important of psychrotolerant fungi to Antarctica associated with wooden cargo packaging. Antarctic Sci 30 (5): 298-305.

Ing LY, Zin NM, Sarwar A, Katas H. 2012. Antifungal activity of chitosan nanoparticles and correlation with their physical properties. Int J Biomater 2012: 1-9.

Jantamas S, Matan N, Matan N. 2013. Effect of tangerine oil against Aspergillus niger identified from raw and boron treated rubberwood. Int J Environ Sci Dev 4 (4): 408-411.

Ketkakomol S, Lerksomlan T, Clement-Vidal A, Chantuma P, Sriroth K, Liengprayoon S, Thaler P, Drevet P, Kasemsap P, Piyachomkwan K, Gohet E, Lacote R. 2014. Starch synthesis and mobilization on wood and bark of rubber tree, in relation with latek production, (1) methodological approach. Adv Mat Res 844: 15-19.

Meijer M, Houbraken JAMP, Dalhuijsen S, Samson RA, de Vries RP. 2011. Growth and hydrolase profiles can be used as characteristics to distinguish Aspergillus niger and other black aspergilli. Stud Mycol 69: 19-30.

Nampally M, Rajulu MBG, Gillet D, Suryanarayanan TS, Moerschbacher B. 2015. A high diversity in chitinolytic and chitosanolytic species and enzymes and their oligomeric products exist in soil with a history of chitin and chitosan exposure. Biomed Res Int 2015: 1-8.

OldertrØen K, H-Kittikun A, Phongpaichit S, Riyajan S, Teanpaisal R. 2016. Treatment of rubberwood (Hevea brasiliensis) (willd. ex. a juss) mull. arg. with maleic anhydride to prevent moulds. J For Sci 62 (7): 314-321. 
Pratheesh KPM, Bharathi HBD, Sivaprasad V. 2017. Antifungal effect of chitosan on certain soil-borne fungal pathogens of mulberry (Morus spp.). Int J Sci 4 (11): 4-11.

Riyaphan J, Phumichai T, Neimsuwan T, Witayakran S, Sungsing K, Kaveeta R, Phumichai C. 2015. Variability in chemical and mechanical properties of Pará rubber (Hevea brasiliensis) trees. Sci Asia 41: 251-258.

Samson RA, Visagie CM, Houbraken J, Hong SB, Hubka V, Klaassen CHW, Perrone G, Seifert KA, Susca A, Tanney JB, Varga J, Kocsube S, Szigeti G, Yaguchi T, Frisvad JC. 2014. Phylogeny, identification and nomenclature of the genus Aspergillus. Stud Mycol 78: 141-183.

Schmidt O, Magel E, Frühwald A, Glukhykh L, Erdt K, Kaschuro S 2016. Influence of sugar and starch content of palm wood on fungal development and prevention of fungal colonization by acid treatment. Holzforschung 70 (8): 783-791.

Silva DM, Batista LR, Rezende EF, Fungaro MHP, Sartori D, Alves E. 2011. Identification of fungi of the genus Aspergillus section nigri using polyphasic taxonomy. Braz J Microbiol 42: 761-773.

Singh T, Vesentini D, Singh AP, Daniel G. 2008. Effect of chitosan on physiological, morphological and ultrastructural characteristics of wood-degrading fungi. Int Biodeterior Biodegrad 62: 116-124.

Waewthongrak W, Pisuchpen S, Leelasuphakul W. 2015. Effect of Bacillus subtilis and chitosan applications on green mold (Penicillium digitatum Sacc.) decay in citrus fruit. Postharv Bio Technol 99: 4449

White TJ, Bruns T, Lee S, Taylor J. 1990. Amplification and direct sequencing of fungal ribosomal RNA genes for phylogenetics. In: Innis MA, Gelfand DH, Sninsky JJ, White TJ (eds) PCR Protocols: A Guide to Methods and Applications. Academic Press, New York.

Wilson ER, Smalling KL, Reilly TJ, Gray E, Bond L, Steele L, Kandel P, Chamberlin A, Gause J, Reynolds N, Robertson I, Novak S, Feris K, White MW. 2014. Assessing the potential effects of fungicides on nontarget gut fungi (Trichomycetes) and their associated larval black fly hosts. J Am Water Resour Assoc 50 (2): 420-433.

Zhang J, Cao H, Li S, Zhao Y, Wang W, Xu Q, Du Y, Yin H. 2015. Characterization of a new family 75 chitosanase from Aspergillus sp. W-2. Int J Biol Macromol 81: 362-369.

Zivanovic S, Davis RH, Golden DA. 2015. Chitosan as an Antimicrobial in Food Products. In: Taylor TM (eds) Handbook of Natural Antimicrobials for Food Safety and Quality. Woodhead Publishing, Cambridge.

Zu G, Chen M, Zhang C. 2012. Screening, identification of a marine fungal strain producing chitosanase. Adv Mat Res 581-582: 11891192. 